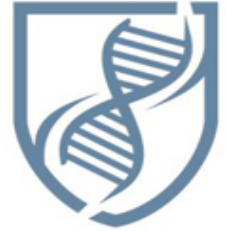

Journal of Bioscience and Applied Research

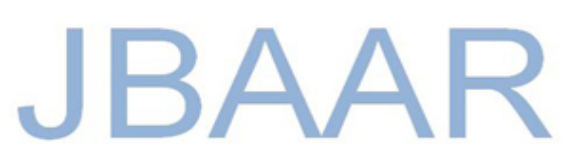

WWW.JBAAR.ORG

\title{
Screening for viral infection and anemia among pregnant women with bad pregnancy outcome in Egyptian population
}

\author{
Amer, A. ${ }^{1}$, Mona, K. Farag ${ }^{1}$, Khaled, R. Gaber ${ }^{1}$, AlKhazindar, M. ${ }^{2}$ and ElSayed, T. ${ }^{2}$ \\ 1. Prenatal Diagnosis and Fetal Medicine Department, National Research Centre, Egypt. \\ 2. Botany and Microbiology Department, Faculty of Science, Cairo University, Egypt. \\ (Corresponding author email: ahmed.amer87@hotmail.com)
}

\begin{abstract}
Hepatitis C virus (HCV) is a major public health concern worldwide and in Egypt. Viral hepatitis during pregnancy is closely related to high risks of maternal complications Human Cytomegalovirus (CMV) is considered the most common cause of congenital malformation that results from viral intrauterine infection in developed countries. Anemia is one of the common complications that is associated with increased risk of bad pregnancy outcome including low birth weight and preterm birth. The aim of this study was to screen for HCV, CMV and anemia among pregnant women in Egyptian population. This prospective study was conducted at the Prenatal Diagnosis clinic in the National Research Centre between April 2013 and August 2015 and a total of 200 pregnant women during their second trimester of pregnancy were enrolled and divided into case group (150/200) with current or history of bad pregnancy outcome and control group (50/200) with no previous history of bad pregnancy outcome. All blood samples were tested for complete blood picture and liver enzyme tests and were screened by ELISA for Anti-HCV and CMV-IgG and IgM. After all investigations including medical and family history for all pregnant women included in the study, all data was statistically analyzed using spss version 19. Anemia was diagnosed in pregnant women with hemoglobin level below $11 \mathrm{~g} / \mathrm{dl}$ and it was detected in $24 \%$ (48/200) of the total pregnant females included in the study. Five cases tested positive for Anti-HCV antibody among all cases enrolled in the study and was found in the cases group 3.33\% (5/150) while all pregnant women in the control group showed negative results. Screening for CMV showed $100 \%$ CMV-IgG while we found $0 \%$ CMV-IgM. Screening for anemia and serological screening for CMV
\end{abstract}

and HCV antibodies should be routine tests especially among pregnant women.

Keywords: Hepatitis C Virus, Cytomegalovirus, anemia, bad pregnancy outcome

\section{Introduction}

Reducing maternal mortality and pregnancy complication will depend on identifying and improving those services that are critical to the health of Egyptian women and girls, including antenatal care, emergency obstetric care, and adequate postpartum care for mothers and babies, and services for family planning, viral infection such as hepatitis C virus and cytomegalovirus (AbouZahr and Wardlaw, 2005).

Viral infections during pregnancy contribute towards maternal morbidity and mortality and are associated with adverse pregnancy outcomes including spontaneous abortion, stillbirth, and prematurity and low birth weight. Furthermore, some infections can be transmitted vertically to neonates, leading to subsequent neonatal morbidity and mortality (Lozano et al., 2011). Hepatitis C Virus (HCV) is a major public health concerned worldwide and in Egypt. It is estimated that its prevalence is $2-3 \%$ throughout the world; with $130-170$ million HCV-positives people, most of them chronically infected (Lavanchy, 2009). The worldwide prevalence of $\mathrm{HCV}$ infection in pregnant women is estimated to be between 1\% and 8\% (Arshad et al., 2011). Egypt has a high prevalence of HCV among pregnant women in Africa (8.6\%) as reported by Yahia, (2011); AbdulQawi et al., (2010). 
Several studies have been conducted to evaluate the contribution of HCV to adverse pregnancy outcomes, $\mathrm{Lu}$ et al., (2012) found that viral hepatitis during pregnancy is associated with high risks of maternal complications including premature rupture of membranes, premature contractions, preterm delivery, placental separation, vaginal bleeding, preterm labor, gestational diabetes mellitus and mortality, with a high rate of vertical transmission resulting in fetal and neonatal hepatitis.

Human Cytomegalovirus (HCMV) is considered the most common cause of congenital malformation that results from viral intrauterine infection in developed countries (Manicklal et al., 2013). The fetal consequences of CMV infection have made it one of the most serious infections contracted during pregnancy. Its clinical manifestations range from asymptomatic forms (90\% of cases) to severe fetal damage that may include sensorineural hearing loss, neurological impairment and in rare cases fetal death (Cannon et al., 2010).

Anemia is a common worldwide problem that is associated with nonspecific complaints affecting about a quarter of the people globally and the most common hematological disorder seen in pregnancy (Janz et al., 2013); (Annamraju and Pavord, 2016). During pregnancy, there is significant change in maternal hemostatic profile resulting in hemoglobin dilution due to the expanding serum component of the blood (Chandra et al., 2012).

The worldwide prevalence of anemia among pregnant women according to World Health Organization is 69\%. In Egypt, the prevalence of anemia in pregnancy was reported to be around 45\% (De Benoist et al., 2008).The aim of this study was to screen for HCV, CMV and anemia among pregnant women with bad pregnancy outcome.

\section{Subject and Methods: \\ 1.Sample Collection}

This prospective study was conducted after the approval of the Medical Ethics Committee in the National Research Centre. It included 200 pregnant females attending the Prenatal Diagnosis \& Fetal Medicine clinic at National Research Centre between April 2013 and August 2015. All samples were collected in the second trimester of pregnancy after taking informed consent and divided into 2 groups:

Case group: which include 150 pregnant with previous history of neural tube defects, congenital anomalies and miscarriage or current pregnant women with fetal congenital abnormalities. Control group: which include 50 pregnant with no previous history of bad pregnancy outcome or any abnormalities detected in current pregnant. Full medical history of all cases enrolled in the study and detailed ultrasound examination for the fetus during the second trimester of pregnancy (16-22 weeks of gestation) was recorded

\section{Blood collection and serum storage:}

Ten ml of blood of blood was collected by venipuncture into into anticoagulant tube with EDTA for $\mathrm{CBC}$ and serum separator tubes then left for $30 \mathrm{~min}$ to facilitate clotting. The clotted samples were then centrifuged at $4000 \mathrm{rpm}$ for $10 \mathrm{~min}$ to separate the serum from the blood cells. The serum was divided into aliquots and stored at $-20{ }^{\circ} \mathrm{C}$ until used. The 200 cases were subjected to several investigations including complete blood picture (Anemia was diagnosed in pregnant women with hemoglobin level below $11 \mathrm{gm} / \mathrm{dl}$. It is further divided into three grades mild anemia (Hb: 10-10.9 g/dl), moderate anemia (Hb: 7-9.9 g/dl) and severe anemia $(\mathrm{Hb}<7 \mathrm{~g} / \mathrm{dl})$ according to (World Health Organization, 2011). Liver enzyme tests which includes (Alanine aminotransferase, Aspartate aminotransferase and Alkaline phosphatase) using spectrophotometer and antibody screening against CMV, HCV.

\section{Liver enzyme tests:}

\subsection{ALT (Alanine aminotransferase):}

This assay was carried out using (Biosystems S.A. Spain) and the procedure was carried out according to the manufacture instruction.

\subsection{AST (Aspartate aminotransferase):}

This assay was carried out using (Biosystems S.A. Spain) and the procedure was carried out according to the manufacture instruction.

\subsection{Alkaline phosphatase (ALP):}

This assay was carried out using (Spectrum - Germany) and the procedure was carried out according to the manufacture instruction.

\section{Antibody screening: \\ 4.1.Anti-CMV for IgG \& IgM:}

This assay was carried out using (Virion/serion ELISA classic cytomegalovirus IgG/IgM, Germany).The reaction is based on the specific interaction of antibodies with their corresponding antigen. The test strips of the SERION ELISA classic microtiter plate are coated with specific antigens of the pathogen of interest. If antibodies in the patient's serum sample are present, they bind to the fixed antigen.

\subsection{Anti-HCV:}

This assay was carried out using (ABBOTT Murex anti$\mathrm{HCV}$ version 4.0, U.K). The reaction based on the specific interaction of any anti-HCV antibodies in the sample with the immobilised antigens in the microwells which were coated with highly purified antigens that contain sequences from the core, NS3, NS4 and NS5 regions of HCV

\section{Statistical methods:}

This prospective study was statistically analyzed using Statistical Package for Social Sciences (SPSS) computer program (version 19 windows) was used for data analysis of $\mathrm{P}$ value, mean and standard deviation and calculating the Odds ratio and 95\% confidence intervals.

\section{Results}

This study included 200 pregnant women and the mean age of the participants in the case group was $27.55 \pm$ 4.69 years including 37 cases showed medic al and family history of hypertension and diabetes. While the mean age of the control was $26.62 \pm 5.76$ years, 9 of them showed 
medical and family history of hypertension and diabetes as listed in table (1).

The mean hemoglobin concentration among the participants was $12.5 \mathrm{gm} / \mathrm{dl} \pm 1.33$. The overall prevalence of anemia in the study was found in $24 \%$ (48/200). Anemia among the case group and the control group was $25.3 \%$ $(38 / 150)$ and $20 \%(10 / 50)$ respectively. $(\mathrm{OR}=1.357 ; 95 \%$ $\mathrm{CI}=0.6193$ to 2.9742, $\mathrm{p}=0.4455)$.

All the anemic pregnant females were divided into microcytic hypochromic anemia which includes 17/48 (35.5\%) and normocytic normochromic anemia which include $31 / 48$ (64.5\%). Of the anemic pregnant women, 35 females (72.9 \%) had mild anemia with hemoglobin ranged from (10.0 - $10.9 \mathrm{gm} / \mathrm{dl})$ and 13 females (27.1 \%) had moderate anemia with hemoglobin ranged $(7.0-9.9 \mathrm{gm} / \mathrm{dl})$ while no case showed severe anemia with hemoglobin $<7.0$ $\mathrm{gm} / \mathrm{dl}$ as shown in figure (1).

All 150 cases were referred with different bad pregnancy outcome which includes, 74 cases with previous history of Recurrent Pregnancy Loss (RPL), 30 cases with previous history of fetal and neonatal death, 25 cases with CNS anomalies divided into ( 2 cases with history of microcephaly, 7 cases with history showed negative results. of hydrocephaly, 8 cases with history of neural tube defect and 8 cases with current neural tube defect), 17 cases with history of Down syndrome and 4 cases with history of multiple congenital anomalies as shown in figure (2).

\section{Cytomegalovirus (CMV-IgG and CMV-IgM).}

All cases showed positive results to CMV-IgG and negative results to CMV-IgM (Odds ratio $=2.98 ; 95 \%$ Confidence interval 0584 to 152.1592, $\mathrm{p}=0.5863$ ). Screening of CMV among case and control group showed in Table (2) and table ( $3=0$.$) .$

\section{Hepatitis C Virus antibody (Anti-HCV)}

Five cases tested positive for Anti-HCV antibody

Table (1): Demographic characteristics of the studied groups.

\begin{tabular}{|c|c|c|c|}
\hline & & $\begin{array}{c}\text { Cases } \\
\mathbf{N}=\mathbf{1 5 0}\end{array}$ & $\begin{array}{c}\text { Control } \\
\mathbf{N}=\mathbf{5 0}\end{array}$ \\
\hline \multicolumn{2}{|c|}{ Age (years) } & $27.55 \pm 4.69$ & $26.62 \pm 5.76$ \\
\hline \multirow{2}{*}{ Medical history: } & Diabetes & 2.0 & 0.0 \\
\hline & Hypertension & 12.0 & 4.0 \\
\hline \multirow[t]{2}{*}{ Family history: } & Diabetes & 14.0 & 2.0 \\
\hline & Hypertension & 9.0 & 3.0 \\
\hline
\end{tabular}

$( \pm)$ mean \pm standard deviation, $(N)$ number of cases.

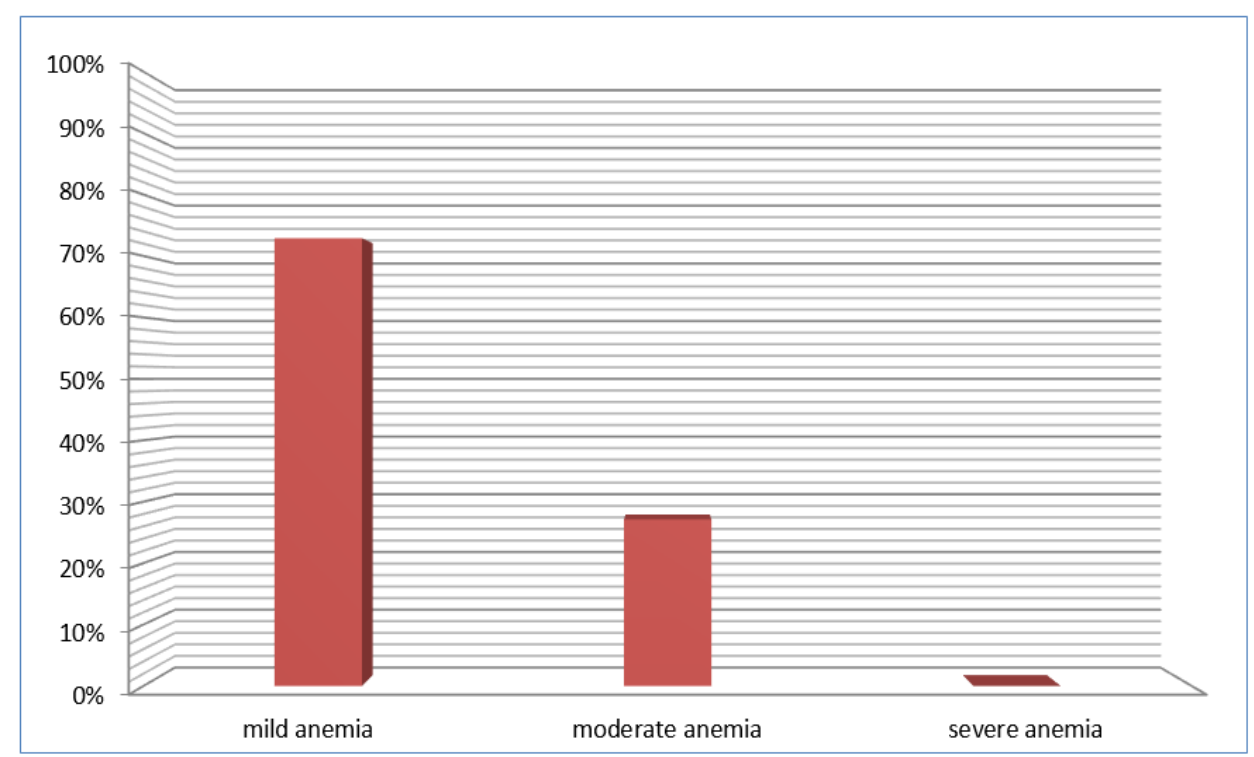

Figure (1): Percentage of anemia by severity among anemic pregnant women. 
among all cases enrolled in the study and was found in the cases group $3.33 \%$ (5/150) while all pregnant women in the control group showed negative results. (Odds ratio= 3.8179; $95 \%$ confidence interval $=0.2074$ to 70.2773 , $\mathrm{p}=0.3673$ ) with elevated liver enzymes as shown in table (4).

\section{Discussion}

Bad pregnancy outcome is defined as previous unfavorable outcome with more than 2 successive spontaneous miscarriage, history of intrauterine fetal death (IUFD), history of intrauterine growth restriction (IUGR), still birth, neonatal death or congenital anomalies. It can be due to genetic, hormonal, abnormal maternal immune response and maternal infection. The incidence of these infections varies from one geographic area to another (Kumari et al., 2011). Of these bad pregnancy outcomes is recurrent spontaneous miscarriage and in this study the incidence of recurrent miscarriage was 49\% (74/150) of the total cases enrolled in the study with different bad pregnancy outcome.

Fetal and neonatal death which is also one of the bad pregnancy outcomes often occurs due to the hypertensive disease of pregnancy, congenital anomalies and various types of maternal infection (Lown et al., 2011). In our study we found that the incidence of Fetal and neonatal death was 20\% (30/150).

Congenital anomaly is defined as structural or functional anomaly that occurs during intrauterine life and can be detected prenatally at birth or can be detected later in infancy (Shawky and Sadik, 2011). In this study congenital anomalies were found in30.6\% (46/150). Central nervous system anomalies were the most common at $16.6 \%(25 / 150)$ and Down syndrome and were found in $11.33 \%(17 / 150)$ followed by multiple congenital anomalies in $2.7 \%$ (4/150) of the total cases enrolled in the study with bad pregnancy outcome.

Several studies explained the role of chronic HCV on pregnancy and pregnancy outcomes. In (2011), a study by Connell et al., found that women with positive HCV were more likely to have infants born preterm, with low birth weight and congenital anomalies. Elinav et al., (2006) and Lu et al., (2012) found that viral hepatitis during pregnancy is closely related to high risks of maternal complications including premature rupture of membranes, premature contractions, preterm delivery, placental separation, vaginal bleeding, preterm labor, gestational diabetes mellitus and mortality, with a high rate of vertical transmission resulting in fetal and neonatal hepatitis.

Egypt has a high prevalence of HCV among pregnant women 8.6\% (AbdulQawi et al., 2010; Yahia, 2011).another studies by (El-Zanaty and Way 2009; Mostafa et al., 2010) have reported that, the transmission rate of $\mathrm{HCV}$ in Egypt is in progress and its prevalence rates have been estimated at 2.4 per 1,000 person- years (165,000 new infections annually). In our study Anti-HCV screening was performed in all cases enrolled in the study and we found $2.5 \%(5 / 200)$ showed positive results and were presented in the case group, while all women screened in the control group showed negative results $(\mathrm{OR}=3.8179 ; 95 \% \mathrm{CI}=0.2074$ to 70.2773 , $\mathrm{p}=0.3673)$.

The seroprevalence of CMV varies greatly with a variety of epidemiological factors such as geographical distribution and socioeconomic status (Bawaraju et al., 2011).

Several studies from Middle Eastern countries have reported a high seroprevalence of CMV IgG in pregnant women and a low prevalence of CMV IgM as evaluated by Bagheri et al., (2012); Al-Awadhi et al., (2013).

In 2014, Zhang et al., found that the overall seroprevalence of anti-CMV IgG was $98.7 \%$, while the anti-CMV IgM seroprevalence was $3.8 \%$. This is in accordance with our results which showed $100 \%$ positive serological screening for IgG while we found $0 \%$ of serological screening for $\operatorname{IgM}(\mathrm{OR}=2.98$; $95 \% \mathrm{CI}=$ 0.0584 to $152.1592, p=0.5863$ ) which an indication of past infection and not experiencing a recent infection.

Anemia is one of the common complications that is associated with increased risk of bad pregnancy outcome including low birth weight and preterm birth (Wong et al., 2016). Prevalence of anemia among population is commonly used through determination of hemoglobin (Hb) and the cut-off levels of $\mathrm{Hb}$ differs according to age, sex and physiological status has been set by (World health organization, 2001). In pregnancy, anemia is present the Hemoglobin level $(\mathrm{Hb})<11 \mathrm{~g} / \mathrm{dl}$. It is further divided into three grades mild anemia (Hb: 10-10.9 g/dl), moderate anemia (Hb 7-9.9 g/dl) and severe anemia ( $\mathrm{Hb}<7 \mathrm{~g} / \mathrm{dl})$.

Although anemia can occur at any age and affect either gender, it is more prevalent in pregnant women and young children. The worldwide prevalence of anemia among pregnant women according to World Health Organization is 69\%. In Egypt the prevalence of anemia in pregnancy was reported to be around $45 \%$ with mild and moderate degrees mainly (De Benoist et al., 2008). In accordance with our study, all the anemic pregnant females showed mild and moderate anemia while none of them showed severe anemia. Other study reported that the prevalence of anemia among pregnant women in Egypt was $45.4 \%$ up to $56 \%$ (Klemm et al., 2011).

Most studies were carried in the third trimester of pregnancy when progressive decrease of hemoglobin level with progress of pregnancy is known. As reported in a study by (El Ashiry et al., 2014) the prevalence of anemia in third trimester was $67 \%$. While in our study anemia was screened in pregnant women during their second trimester of pregnancy and it was found in $24 \%$ (48/200) of the total pregnant females included in the study. Anemia among the case group and the control group was 25.3\% (38/150) and $20 \%(10 / 50)$ respectively. $\quad(\mathrm{OR}=1.357 ; 95 \% \quad \mathrm{CI}=$ 0.6193 to $2.9742, p=0.4455)$. The strength of this study is the use of prospectively collected information from antenatal visit. 


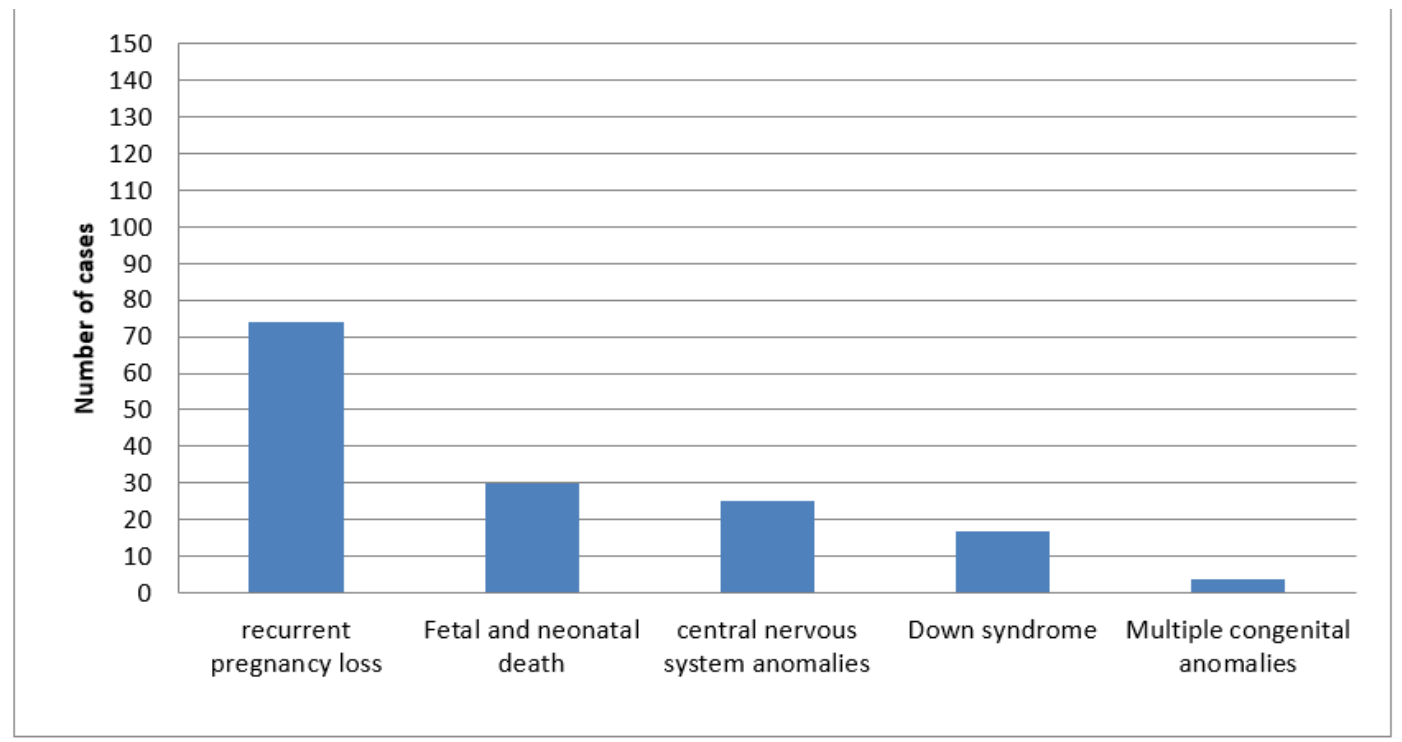

Figure (2): Studied cases with bad pregnancy outcome.

Table (2): Screening for CMV among case group

\begin{tabular}{|c|c|c|c|c|c|}
\hline & $\mathbf{N}$ & Minimum & Maximum & Mean & Std. Deviation \\
\hline CMV-IgG & 150 & 1.10 & 1.95 & 1.439 & 0.219 \\
\hline CMV-IgM & 150 & 0.11 & 0.53 & 0.277 & 0.0774 \\
\hline
\end{tabular}

Table (3): Screening for CMV among control group

\begin{tabular}{|c|c|c|c|c|c|}
\hline & $\mathbf{N}$ & Minimum & Maximum & Mean & Std. Deviation \\
\hline CMV-IgG & 50 & 1.100 & 1.900 & 1.43580 & .239106 \\
\hline CMV-IgM & 50 & .120 & .610 & .39180 & .133259 \\
\hline
\end{tabular}

Table (4): Clinical characteristics of positive Anti-HCV cases.

\begin{tabular}{|c|c|c|c|c|c|c|c|}
\hline Cases & $\begin{array}{c}\text { Anti- } \\
\text { HCV } \\
(>0.69)\end{array}$ & $\begin{array}{c}\text { Age } \\
\text { (years) }\end{array}$ & $\begin{array}{l}\text { Cause of } \\
\text { referral }\end{array}$ & CBC & $\begin{array}{c}\text { ALT } \\
>40 \mathrm{U} / \mathrm{L}\end{array}$ & $\begin{array}{c}\text { AST } \\
>40 U / L\end{array}$ & $\begin{array}{c}\text { ALP } \\
(40- \\
170 I U / L)\end{array}$ \\
\hline $\mathbf{1}$ & 3.44 & 22 & H/o RPL & Normal & 140 & 102 & 100 \\
\hline 2 & 3.95 & 28 & $\begin{array}{l}\text { H/o Down } \\
\text { Syndrome }\end{array}$ & Normal & 310 & 190 & 200 \\
\hline 3 & 2.1 & 25 & H/o RPL & Normal & 192 & 100 & 190 \\
\hline 4 & 3.11 & 30 & $\begin{array}{l}\text { H/o neonatal } \\
\text { death }\end{array}$ & Normal & 150 & 90 & 180 \\
\hline 5 & 2.35 & 36 & H/o RPL & $\begin{array}{c}\text { Normocytic } \\
\text { normochromic } \\
\text { anemia }\end{array}$ & 170 & 114 & 176 \\
\hline
\end{tabular}




\section{Conclusion}

Based on the finding of the study we concluded that pregnant female should screened early for anemia and managed on multivitamin supplementation in order to increase their hemoglobin level and the detection of anemia and its treatment should be available in all health care. On the other hand CMV antibodies should be routinely screened due to the $100 \%$ seroprevalence of CMV-IgG and 0\% CMV-IgM which an indication of past infection of CMV which in turn make them in a risk of virus reactivation. Also routine screening for Anti-HCV antibody as it can be presented and detected by accidental finding as happened in screened pregnant women in our study and they do not know before our investigations that they had positive Anti-HCV antibodies and were referred to health personnel after telling them.

\section{References}

AbdulQawi, K.; Youssef, A.; Metwally, MA.; Ragih, I.; AbdulHamid, M.; Shaheen, A. (2010) Prospective study of prevalence and risk factors for hepatitis $\mathrm{C}$ in pregnant Egyptian women and its transmission to their infants. Croat Med J 51: 219-228.

AbouZahr, C. and Wardlaw, T. (2004) Maternal mortality in 2000: estimates developed by WHO, UNICEF and UNFPA. Geneva: ISBA 924 1562706.

Al-Awadhi, R.; Al-Harmi, J.; Alfadhli, S. (2013). Prevalence of cytomegalovirus DNA in cord blood and voided urine obtained from pregnant women at the end of pregnancy. Med PrincPract; 22: 194-199.

Annamraju, H. and Pavord, S. (2016). Anemia in pregnancy. Br J Hosp Med (Lond). 77 (Sup10):584-588.

Arshad, M.; El-Kamary, SS.; Jhaveri, R. (2011). Hepatitis C virus infection during pregnancy and the newborn period--are they opportunities for treatment? J Viral Hepat. (4):229-36.

Bagheri, L.; Mokhtarian, H.; Sarshar, N.; Ghahramani, M. (2012). Seroepidemiology of cytomegalovirus infection during pregnancy in Gonabad, east of Iran: a cross-sectional study. J Res Health Sci. 12: 38-44.

Bawaraju, A.; Mane, PM.; Vijayadurga, S. (2011). The reactivation of the cytomegalovirus (CMV) infection in HIV infected patients. J Clinical and Diagnostic Research, 5(4):749-751.

Cannon, M.J.; Schmid, D.S.; Hyde, T.B. (2010). Review of cytomegalovirus seroprevalence and demographic characteristics associated with infection. Rev Med Virol. 20(4):202-213.

Chandra, S.; Tripathi, A. K.; Mishra, S.; Amzarul, M.; Vaish, A. K. (2012). Physiological Changes in Hematological Parameters During
Pregnancy. Indian J Hematol Blood Transfuse. 28(3):144-146.

Connell, LE.; Salihu, HM.; Salemi, JL.; August, EM.; Weldeselasse, H.; Mbah, AK. (2011). Maternal hepatitis B and hepatitis C carrier status and perinatal outcomes. 31: 1163-1170

De Benoist, B.; McLean, E.; Egli, I.; Cogswell, M. (2008). Worldwide Prevalence of Anaemia 1993-2005 WHO Global Database on Anaemia. Geneva, World Health Organization. 2008: 21. No. of pages: 40. ISBN 9789241596657.

El Ashiry, A.; El Ghazali S.; Habil, I. (2014). Prevalence and determinant of anaemia in third trimester pregnancy in Fayoum Governorate-Egypt. Acta Medica Mediterranea, 30: 1045-1050

Elinav, E.; Ben-Dov, IZ.; Shapira, Y.; Daudi, N.; Adler, R.; Shouval, D.; Ackerman, Z. (2006). Acute hepatitis A infection in pregnancy is associated with high rates of gestational complications and preterm labor. Gastroenterology 130: 1129-1134.

El-Zanaty, F. and Way, A. (2009) Egypt demographic and health survey 2008. Cairo, Egypt: Ministry of Health, El-Zanaty and Associates, and Macro International, Cairo Egypt.

Janz, TG.; Johnson, RL.; Rubenstein, SD. (2013). Anemia in the emergency department: evaluation and treatment. Emerg Med Pract. 15 (11):115.

Klemm, R.; Sommerfelt, AE.; Boyo, A.; Barba, C.; Kotecha, P.; Steffen, M.; Franklin, N. (2011) Are We Making Progress on Reducing Anaemia in Women? Cross-country Comparison of Anaemia Prevalence, Reach, and Use of Antenatal Care and Anaemia Reduction Interventions. AED, under the terms of Cooperative Agreement No. GHSA- 00-05-00012-00. No of pages: 69

Kumari, N.; Morris, N.; Dutta, R. (2011). Is Screening of TORCH Worthwhile in Women with Bad Obstetric History: An Observation from Eastern Nepal. J Health Popul Nutr. 29(1): 77-80.

Lavanchy, D. (2009). The global burden of hepatitis C. Liver Int.29 (Suppl 1), 74-81.

Lown, E.; Hannah, B.; Robert, P.; Simon, C.; Rajesh, K.; Ibinabo, I.; Jason, G.; Louise, T.; Cynthia, S. (2011). Stillbirth: Where? When? Why? How to make the data count. 377(9775):1448-1463.

Lozano, R.; Wang, H.; Foreman, K.J.; Rajaratnam, J.K.; Naghavi, M.; Marcus J.R. (2011). Progress towards Millennium Development Goals 4 and 5 on maternal and child mortality: an updated systematic analysis. Lancet 378:1139-1165.

Lu, Y.; Chen, Y.; Xiao, X.; Liang, X.; Li, J.; Huang, S.; Chen, X.; Hocher, B. (2012). [Impact of maternal hepatitis B surface antigen carrier status on preterm delivery in southern China]. Nan Fang Yi Ke Da XueXueBao. 32:1369-1372. 
Manicklal, S.; Emery, VC.; Lazzarotto, T. (2013) The 'silent' global burden of congenital cytomegalovirus.ClinMicrobiol Rev; 26: 86-102.

Mostafa, A.; Taylor, SM.; El-Daly, M.; El Hoseiny, M.; Bakr, I.; Arafa, N.; Thiers, V.; Rimlinger, F.; Abdel-Hamid, M.; Fontanet, A.; Mohamed, MK. (2010). Is the hepatitis C virus epidemic over in Egypt? Incidence and risk factors of new hepatitis C virus infections. Liver Int. 30(4):560566.

Shawky, R. M.; Sadik, D. I. (2011). Congenital malformations prevalent among Egyptian children and associated risk factors. The Egyptian J Medical Human Genetics. 12: 69-78.

Wong, L.; Smith, S.; Gilstrop, M.; Derman, R.; Auerbach, S.; London, N.; Lenowitz, S.; Bahrain, H.; McClintock, J.; Auerbach, M. (2016) Safety and efficacy of rapid (1,000 mg in $1 \mathrm{hr}$ ) intravenous iron dextran for treatment of maternal iron deficient anemia of pregnancy. Am. J. Hematol. Wiley Periodicals, Inc. 91:590-593.

World Health Organization (2011). Hemoglobin Concentrations for the Diagnosis of Anemia and Assessment of Severity, Vitamin and Mineral Nutrition Information System. Geneva, Switzerland: $\quad$ WHO reference number: WHO/NMH/NHD/MNM/11.1.

World Health Organization (2001). Iron Deficiency Anaemia: Assessment, Prevention and Control, A guide for programme managers. Geneva Geneva, Switzerland. Ref. no. WHO/NHD/01.3.

Yahia, M. (2011) Global health: a uniquely Egyptian epidemic. Nature 474: S12-S13.

Zhang, S.; Lingqing, Hu.; Jie Chen; Biyun, Xu.; Yi-Hua Zhou; Yali Hu. (2014) Cytomegalovirus Seroprevalence in Pregnant Women and Association with Adverse Pregnancy/Neonatal Outcomes in Jiangsu Province, China.PLoS One.; 9(9): e10764. 